\title{
Titanium extraction from waste NORM
}

\author{
B.R. Pereira, M.A.G. Silveira, G. Fontana, P.R.S. Santos \\ Centro Universitário da FEI \\ São Bernardo do Campo, S.P., Brazil \\ marcileiafei.edu.br
}

\section{M.A.Rizzutto, N. H. Medina}

Instituto de Física da USP

São Paulo, S.P., Brazil

The constantly growing of global agricultural production depends on the development of a whole production to be lasting and sustainable. The phosphoric acid production is directly related to the production of fertilizers, but its process of obtaining requires numerous steps and generates a lot of waste. There are several elements in some of these wastes that are very valuable and important for economy and for technological development. An example is a residue derived from a step of physical handling of the phosphate rock, containing about $30 \%$ of titanium in its composition. Titanium can be used in various applications, such as a component in high-tech metallic alloys, or, in the form of titanium dioxide, which is the form that presents the greatest value in industry. This study focus at the concentration of titanium oxide present in a residue from the phosphoric acid production, by attacking the material chemically and doing its characterization by analytical methods. This would contribute to the national titanium concentrated production increased and enhance the economic yield of the phosphoric acid production process, by transforming an unused waste in a high value product. The methodology for the concentration of titanium oxide was based in industrial extraction of titanium ores and consists of solubilizing the impurities present in the sample by means of chemical attack. It has been determined experimentally that at temperatures around $70^{\circ} \mathrm{C}$, hydrochloric acid provides a better solubilization of impurities, without extracting titanium, and it is possible to obtain a residual solid phase with about $58.5 \%$ of titanium on it. The results were determined by using the Energy Dispersive X-Ray Fluorescence (EDXRF) technique. As the original sample is a Normal Occurring Radioactive Material (NORM), an analysis of Gamma Ray Spectroscopy and EDXRF were realized to determine how the radionuclides form the $\mathrm{U}$ and $\mathrm{Th}$ series were affected by the chemical treatment.

X Latin American Symposium on Nuclear Physics and Applications (X LASNPA)

1-6 December 2013

Montevideo, Uruguay 


\section{Introduction}

Titanium is the ninth most abundant chemical element in the earth's crust, mainly found in the oxide form, and which ilmenite and rutile are the major mineral raw materials for its extraction. The most remarkable use of titanium is in the dioxide form, covering most of industrial applications such as the manufacture of paints, paper production, rubber, textiles, plastics, and other products worldwide manufacturing. Specifically in Brazil, the largest consumer of titanium is used in the manufacture of paints, enamels and varnishes, followed by the production of steel and iron alloys.

In some processes that use igneous and sedimentary rocks as a source of raw material, titanium is considered a contaminant or a waste, such as in the aluminum production and phosphoric acid production. In the latter, titanium is found in significant quantities in a waste of the phosphate rock physical treatment step, specifically after a separation step that retains the magnetite present in the rock. In this context, it should be considered that phosphoric acid $\left(\mathrm{H}_{3} \mathrm{PO}_{4}\right)$ is an important raw material for the production of phosphate fertilizers of high concentration, which exhibits great importance in the growth of world agricultural demand. This fact shows how great the phosphoric acid production and its waste generation are, and that is very important to reduce the production or to reuse the wastes generated during de production processes. This project was developed with samples, provided by Vale Fertilizantess S.A., a brazilian industry, that consist in a waste from a magnetic separation step of the phosphate rock physical treatment process during phosphoric acid production.

\section{Experimental Procedure}

The residue in question, which is in the solid form, was subjected to a series of solubility tests with temperature around $70^{\circ} \mathrm{C}$ and with constant stirring, using sulfuric acid, hydrochloric acid, nitric acid and sodium hydroxide in order to concentrate the titanium dioxide present in the sample [1,2] . After solubilization, the liquid and solid phases obtained were analyzed using Energy Dispersive X-Ray Fluorescence Spectrometry (EDXRF) [3] in order to qualify and quantify the elements solubilized and the ones that were concentrated in the solid phase. The analysis of both phases by the same technique increased the data reliability and enable to make accurate comparisons of the phases. To verify the crystal structure analysis of this material, a Xray diffraction analysis was performed [4]. In parallel with the solubility test, we performed a magnetic separation of the initial sample to identify how the titanium is present in the material, since the iron oxide is more magnetic than ilmenite, which is more magnetic than titanium dioxide. As the studied waste comes from phosphate rock, which presents radionuclides in its composition, we used the techniques of fluorescence X- ray and Gamma Spectrometry to assess the distribution of radionuclides (belonging to the families of decay of $U$ and $T h$ ) in the sample during the chemical treatment [5,6]. The objective was to verify the behavior of the radionuclides against the proposed methodology. To detect the emitted gamma rays from ${ }^{238} \mathrm{U}$ and ${ }^{232} \mathrm{Th}$, we used a measurement system available at the Centro Universitário da FEI, São Bernardo do Campo, São Paulo, Brazil, consisting of a 3x3-in2 NaI(Tl) scintillation detector placed inside a $7.0 \mathrm{~cm}$ thick lead shield and a spectrometer unit (Canberra, USA) [7-10]. The 
data acquisition and spectra were analyzed using GENIE-2000 software. The determination of effective dose due to external natural radiation was based on measurements of photopeak gamma radiation from ${ }^{214} \mathrm{Bi}$ decay $(1764.5 \mathrm{keV})$ in the ${ }^{238} \mathrm{U}$ decay series and from ${ }^{208} \mathrm{Tl}$ decay $(2614.5 \mathrm{keV})$ in the ${ }^{232} \mathrm{Th}$ decay series. Gamma ray spectra emmitted from the samples collected were acquired during 8 hours. The absorbed gamma-ray dose rates in air, in $\mathrm{nGy} / \mathrm{h}$, were calculated according to Reference [6]. Energy Dispersive Fluorescence X ray technique was used to measure the radionuclide activity from samples with mass lower than $10 \mathrm{~g}$. For this analisis we used a Portable X-Ray Fluorescence Spectrometry system that consist of a MINI-X spectrometer and a Silicon Drift detector from Amptek [11]. The X-ray fluorescence setup uses a mini X-ray tube which operates with voltage from 10 to $50 \mathrm{kV}$ and current of 5 to $200 \mu \mathrm{A}$ with a silver (Ag) transmission target. The detector used is a Si-Drift X-ray semiconductor $\left(25 \mathrm{~mm}^{2}\right.$ $\mathrm{x} 500 \mu \mathrm{m} / 0.5$ mil) with a thin Beryllium end window of $1.5 "$ ", which is a new high performance x-ray detector, with energy resolution of $125 \mathrm{eV} \mathrm{FWHM}$ at @ $5.9 \mathrm{keV}\left({ }^{55} \mathrm{Fe}\right)$, while operating at much higher count rates than a conventional diode. The measurements were carried out with $30 \mathrm{kV}$ voltage applied on the tube, $5 \mu \mathrm{A}$ of tube current and an excitation/detection time of $300 \mathrm{~s}$ (live time). The $\mathrm{U}$ and Th measurements it also used an inner filter of $\mathrm{W}$ and $\mathrm{Al}$ foil in the $\mathrm{x}$-ray tube Spectra were analyzed with QXAS-AXIL software by IAEA (International Atomic Energy Agency).

In both techniques, the activity calibration was performed by using the IAEA quality assurance reference materials: RGU-238, RGTh-232 and RGK-1, prepared in the same geometry of the sample [6].

\section{Results and Analysis}

\section{1. $\quad$ Radionuclide Distribution}

Through the technique of gamma ray spectrometry, it was found high concentrations of natural radionuclides emitting gamma rays: ${ }^{232} \mathrm{Th}$ and ${ }^{238} \mathrm{U}$. The characteristic gamma ray peaks of these radionuclides are show in Figure 1. The presence of the $1460 \mathrm{keV}$ gamma-ray peak is due to the presence of ${ }^{40} \mathrm{~K}$ from the background. The annual effective dose from terrestrial radiation is $(2.26 \pm 0.05) \mathrm{mSv}$. Since this value is higher than the world average: from 0.3 to $1.0 \mathrm{mSv}$, it is necessary to monitor the radionuclide concentration during the titanium extraction process [6]. 


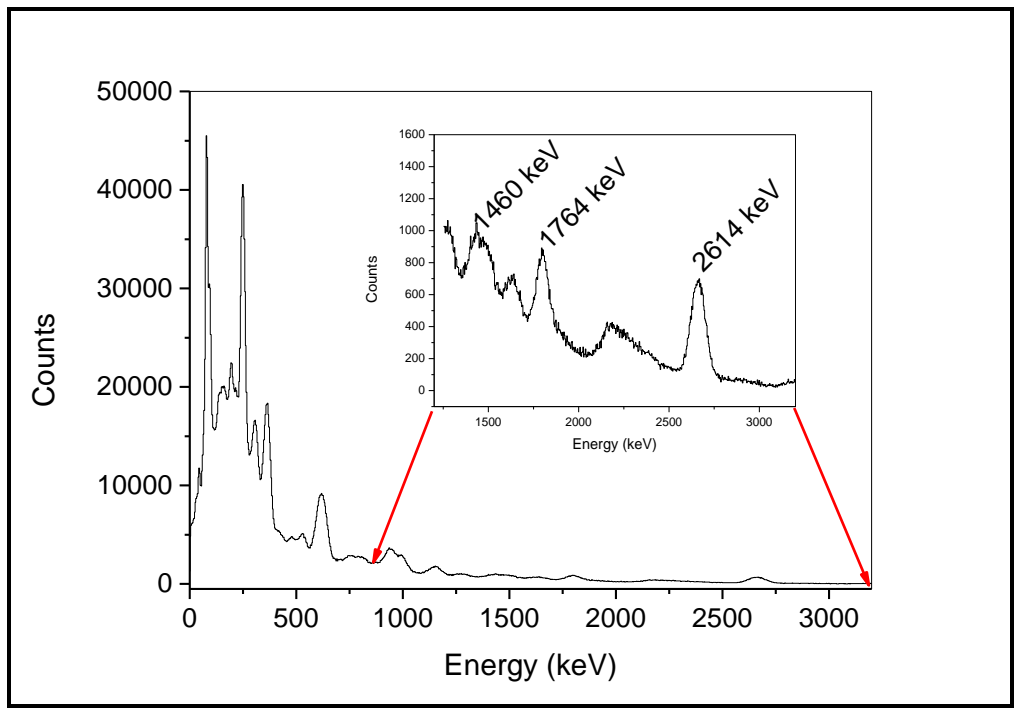

Figure 1: Gamma Ray Spectrum form the original sample with ${ }^{232} \mathrm{Th},{ }^{238} \mathrm{U}$ and ${ }^{40} \mathrm{~K}$ peaks.

\subsection{Magnetic Separation}

The magnetic separation of the original sample showed that the majority of the sample is highly magnetic. The results are presented in the Figure 2.

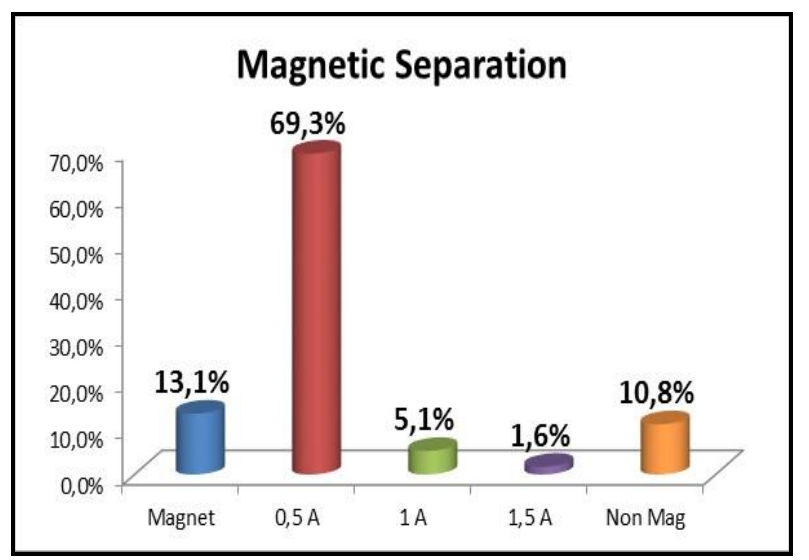

Figure 2: Magnetic sample distribution for five different magnetic levels, provided by the use of a simple magnet and by the variation of the current in an electromagnet $(0.5 \mathrm{~A}-1.5 \mathrm{~A})$.

In Figure 3 Energy-Dispersive Spectroscopy (EDS) with X-Ray microanalysis, using an Oxford $\mathrm{Si}(\mathrm{Li})$ detector, revealed that the iron and titanium are closely linked and concentrated in the highly magnetic fraction and calcium and phosphorus are concentrated in the less magnetic fraction [12]. The results indicate the chemical bond between iron and titanium shows that the sample has a nearby ilmenite structure. This fact indicates that it is required a chemical treatment to separate iron and titanium. 


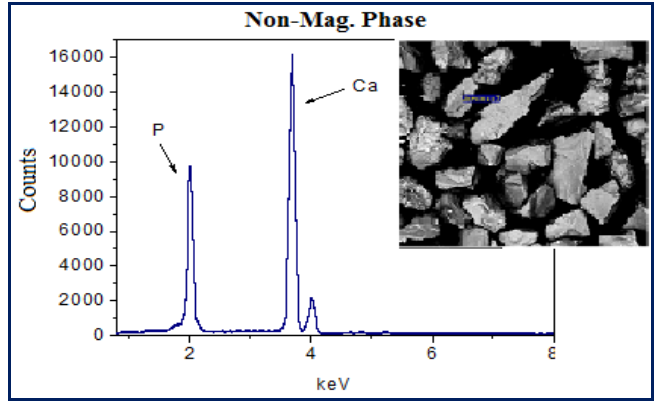

(a)

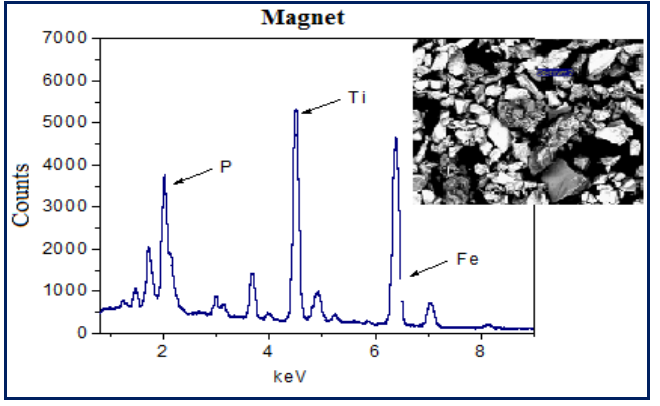

(b)

Figure 3: EDS results for the magnetic separation, a) non-magnetic phase; b) highly magnetic phase.

\subsection{Chemical Treatment and characterization}

After chemical treatment with constant heating and stirring, the residual solid phase of each trial was analyzed using the portable X-ray fluorescence system. Table 1 shows the results of this analysis, where one can observe that the $12 \mathrm{M}$ hydrochloric acid showed the best results, because the solid phase of this trial showed a lower proportion of iron and a higher proportion of titanium when compared with the original sample.

Table1: Solid X-ray fluorescence results. The uncertainty of the obtained values is around 5\%

\begin{tabular}{|c|c|c|c|c|c|}
\hline$\%$ & Original & $\begin{array}{c}\mathrm{H}_{2} \mathrm{SO}_{4} \\
2 \mathrm{M}\end{array}$ & $\begin{array}{c}\mathrm{H}_{2} \mathrm{SO}_{4} \\
5 \mathrm{M}\end{array}$ & $\begin{array}{c}\mathrm{HCl} \\
12 \mathrm{M}\end{array}$ & $\begin{array}{c}\mathrm{HCl} \\
6 \mathrm{M}\end{array}$ \\
\hline $\mathrm{Fe}$ & $\mathbf{4 9 . 6 4}$ & 52.9 & 45.3 & 46.4 & 52 \\
\hline $\mathrm{Ti}$ & $\mathbf{2 7 . 1 9}$ & 22.4 & 24.3 & 45.3 & 40.5 \\
\hline $\mathrm{Mn}$ & $\mathbf{2 . 1 9}$ & 1.6 & 1.5 & 3.9 & 3.3 \\
\hline $\mathrm{Nb}$ & $\mathbf{0 . 8 9}$ & 1.2 & 1.05 & 2.05 & 1.9 \\
\hline $\mathrm{Zr}$ & $\mathbf{0 . 2 9}$ & 0.68 & 0.6 & 1.2 & 1.1 \\
\hline $\mathrm{Ca}$ & $\mathbf{1 2 . 2 1}$ & 12.3 & 15.1 & 0.72 & 0.78 \\
\hline $\mathrm{Zn}$ & $\mathbf{0 . 1 6}$ & - & 0.12 & 0.23 & 0.21 \\
\hline $\mathrm{Sr}$ & $\mathbf{1 . 7}$ & 1.8 & 1.8 & 0.05 & 0.04 \\
\hline
\end{tabular}

The X-ray fluorescence spectrum, presented in Figure 4, compares the liquid and solid phases after the attack with hydrochloric acid. It is possible to verify that titanium was concentrated in the solid phase, as well as zirconium and niobium. On the other hand, part of iron is present in the liquid phase. 


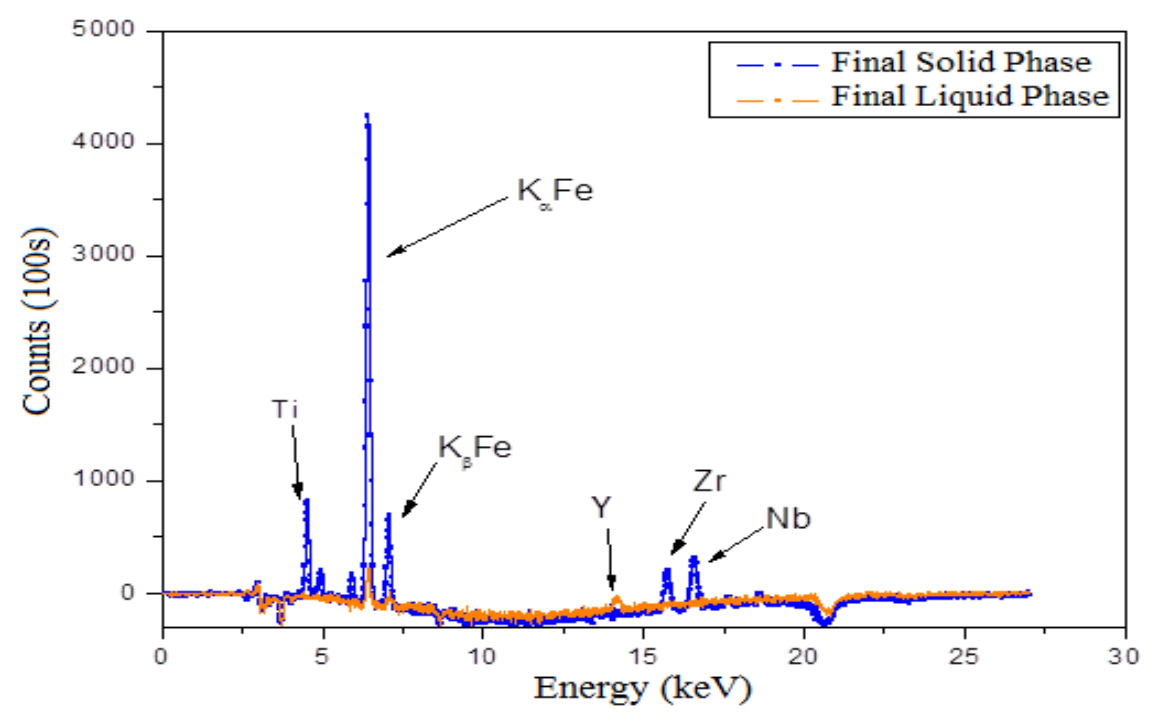

Figure 4: HCL treatment phases X-ray fluorescence spectra

After chemical treatment, the amount of the solid phase sample recovered was about some milligrams, what difficult the gamma ray spectrometry analysis. Therefore, to determine the presence of the radionuclides in the sample we used the EDXRF technique with the portable equipment.



Figure 5: X-ray fluorescence spectrum of solid phase after $\mathrm{HCl}$ treatment. It is possible to observe the presence of Th and $\mathrm{U} \mathrm{X}$-lines.

The use of the references materials RGU-238 and RGTh-232, prepared in the same geometry of the sample, allow the exactly identification of the Th and $U$ L $\alpha$ lines in the XRF spectra. 
Based on the standard spectra, the solid and liquid phases, after the $\mathrm{HCl}$ treatment, were analyzed and compared in Figure 4. It can be noticed that the $U$ and Th are concentrated in the solid phase indicating the $\mathrm{HCl}$ acid is not able to solubilize this elements. The results obtained for the liquid phase did not accuse the presence of these radionuclides.

\subsubsection{Final Solid Phase}

To promote full separation of the phases, the final solid phase, still wet, was centrifuged at $4000 \mathrm{rpm}$ for 20 minutes. After this procedure, the solid phase was separated into two other new phases, one white and another black. The white phase was analyzed by the EDS technique, showing that it is composed primarily of titanium and oxygen, probably in the form of $\mathrm{TiO}_{2}$. In Figure 6 the EDS results is shown.

To determine the crystal structure of the white phase, an analysis of X-ray diffraction was performed using the XRD-7000 Shimadzu. After chemical treatment, the solid phase shows a crystalline structure similar to the rutile, where iron and titanium are not chemically bonded. Figure 7 shows X-ray diffraction spectra where it is possible to see the superposition of the final solid phase spectrum with the standard spectrum of rutile.



Figure 6: (a) Picture showing the white and black phases totally separated. (b) X-ray EDS solid phase spectrum showing the presence of $\mathrm{Ti}$ and $\mathrm{Fe}$.

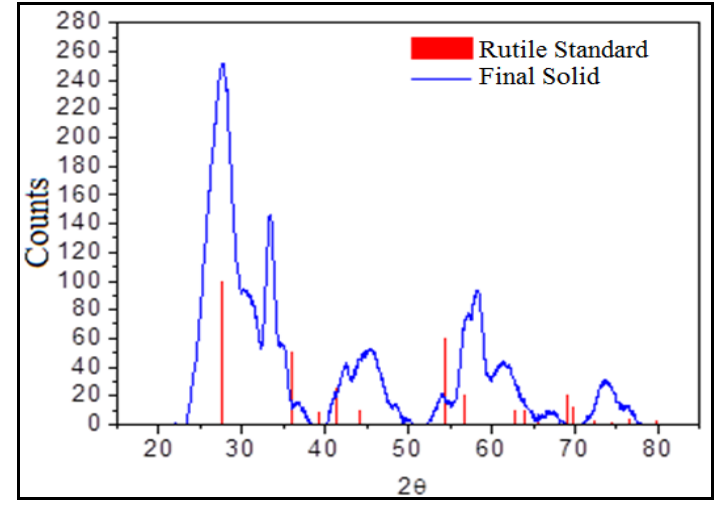

Figure 7: X-ray diffraction spectrum for the white solid phase in comparison with rutile standard 
It can be observed that the spectrum of the sample exhibits peaks in the same regions of the rutile standard spectrum, but slightly offset because the sample did not undergo at proper thermal treatment for the complete formation of the crystal phase.

\section{Conclusion}

In this work we used gamma-ray spectrometry, Energy Dispersive X-Ray Fluorescence and diffraction techniques to study the concentration of Ti to characterize TNORM material after several chemical process stages. According to the composition and the physic-chemical characteristics of the magnetic waste sample, it was possible to perform treatment using hydrochloric acid in order to concentrate the titanium present in the sample. The analysis of Xray fluorescence and EDS showed that it was obtained a phase rich in titanium, niobium and zirconium. The other phase is rich in other contaminants, such as iron. With the analysis of Xray diffraction it was observed that after the treatment, the titanium and iron did not remain chemically linked and the gamma ray spectrometry, in conjunction with the X-ray fluorescence, showed no solubilization of radionuclides which remained concentrated in the final solid phase, indicating a possible interaction of these elements with titanium, niobium and zirconium.

\section{References}

[1] [1] B. Mazumder; B. K. Mishra. Managing Wastes from Aluminum Smelter Plants. Woodhead Publishing. 2010.

[2] [2] A. I. Vogel. Análise química quantitativa. $6^{\circ}$ ed. p. 347-350. LTC. Rio de Janeiro 2002.

[3] [3] Potts, P. J., and M. West (editors) 2008 Portable X-Ray Fluorescence Spectrometry: Capabilities for In Situ Analysis. RSC Publishing, Cambridge, England and references therein.

[4] [4] L. Bleicher; J. M. Sasaki. Introdução à difração de raio X em cristais. Fortaleza: Universidade Federal do Ceará. 2000.

[5] [5] Ullmann's. Encyclopedia of Industrial Chemistry: Parkinsonism Treatment to Photoelectricity. Editor VCH. 1991. v. A19. p. 467-471

[6] [6] UNSCEAR.: Sources and Effects of Ionizing Radiation: Exposures from natural radiation sources. New York. 2000.

[7] [7] Medina, N.H., Silveira, M. A. G., Santos, R. B. B. 2013. Dynamic distribution of potassium in sugarcane. Journal of Environmental Radioactivity. , v.126, p.172 - 175,

[8] [8] M.A.G. Silveira. R.H. Moreira. A.L.C. de Paula. and N.H. Medina. 2009. In: Nuclear Physics 2008: XXXI Workshop on Nuclear Physics in Brazil; ed. Melville. NY: American Institute of Physics Conference Proceedings. 1139. p. 153-155

[9] [9] M.A.G. Silveira et al.. 2010. In: VIII Latin American Symposium on Nuclear Physics and Applications. American Institute of Physics Conference Proceedings. 1265 p. 465-46. 
[10] [10] M.M. Matsumoto. M.A.G. Silveira. N.H. Medina. N.K. Umisedo. The Natural Radiation Environment: 8th International Symposium (NRE VIII). American Institute of Physics Conference Proceedings. 2008. 1034. p. 252-255.

[11] [11] Amptek Company - http://www.amptek.com/products.html - accessed March 2014

[12] [12] V.A.P. Aguiar et al., 2010, International Microscopy Congress, IMC Proceedings 2010, Rio de Janeiro, Brazil, (CD-ROM). 